\title{
A DISTRIBUIÇÃO DO CARANGUEJO DE ÁGUA DOCE, FREDIUS REFLEXIFRONS (ORTMANN, 1897), EM UMA ÁREA DE PROTEÇÃO AMBIENTAL NO PLANALTO DA IBIAPABA - NORDESTE DO BRASIL, COM NOVOS REGISTROS E COMENTÁRIOS SOBRE SUA CONSERVAÇÃO
}

\author{
Santos, L.C. ${ }^{1,}$; Nascimento, W.M. ${ }^{2}$, Pinheiro, A.P. ${ }^{2} \&$ Silva, J.R.F. ${ }^{1}$ \\ ${ }^{1}$ Universidade Federal do Ceará (UFC), Campus do PICl- Fortaleza - CE, \\ Laboratório de Ecologia de Ecossistemas Aquáticos- LEEA. \\ ${ }^{2}$ Universidade Regional do Cariri (URCA), Campus do Pimenta - Crato - CE. \\ Laboratório de Crustáceos do Semiárido - LACRUSE. \\ *Autor correspondente: santos.bio.79@gmail.com
}

\begin{abstract}
Caranguejos de água doce são organismos importantes de ecossistemas aquáticos. A distribuição desses indivíduos no ambiente é restrita por conta das suas características de história de vida o que dificultam as estratégias de conservação. Com ampla distribuição na bacia amazônica, Fredius reflexifrons, encontra-se distribuído de forma relictual em pequenas zonas úmidas, do Planalto da Ibiapaba, Nordeste do Brasil. Por possuir distribuição em escala reduzida, a degradação do habitat, destruição de manchas de floresta, canalização de corpos d'agua e uso da terra para plantação de leguminosas, são sérios impactos que podem levar a extinção das populações relictuais desses caranguejos na Área de Proteção Ambiental da bica do Ipu - Planalto da Ibiapaba. Diante disso, este trabalho teve como objetivos ampliar a distribuição da espécie na Área de Proteção ambiental da Bica do Ipu identificando os principais impactos oriundos da ação antrópica, possíveis medidas para mitigar esses impactos, a sugestão para ampliação da área de proteção ambiental, além de ter sido calculado a Área de Ocupação (AOO) e Área de Ocorrência (EOO). Foram encontrados 11 pontos de ocorrência da espécie no Planalto da Ibiapaba, dos quais, 9 são novos registros, dos quais 5 não estão na Área de Proteção Ambiental, o que evidência a necessidade de expansão da APA para englobar essas localidades, visto que a espécie encontrase ameaçada em escala local.
\end{abstract}

Palavras-chave: semiárido nordestino, distribuição relictual, Pseudothelphusidae, Unidade de Conservação. 